\title{
La frontera y su espacio temporalidad. Aproximaciones a las movilidades y a las relaciones culturales en los Andes ${ }^{1}$
}

\author{
María Cristina Hevilla² y Matías Molina ${ }^{3}$
}

\begin{abstract}
RESUMEN
A lo largo de su historia los Estados de Argentina y Chile han llevado adelante diferente tipo de acciones orientadas a controlar la frontera y las prácticas de sus habitantes. Sin embargo, los grupos pastoriles a través de estrategias de adaptación y resistencia mantienen sus movilidades ancestrales. En este texto se realiza un balance de la trayectoria de investigación que se ha llevado adelante desde el año 2000 en relación a esta temática en el área centro oeste de la frontera argentino chilena. Las preguntas que guían esta revisión son las siguientes: ¿cuáles han sido los giros epistemológicos que orientaron nuestros estudios sobre esta frontera?; ¿qué tipos de representaciones textuales y visuales desarrollamos? Y, por último, ¿qué perspectivas ofreció el estudio caso para cuestionar el paradigma fronterizo en el que nos habíamos formado y proponer nuevas líneas de investigación?.
\end{abstract}

Palabras claves: Frontera, movilidades, relaciones culturales.

\section{ABSTRACT}

Throughout their own history, the states of Argentina and Chile have carried out different kind of actions in order to control borders and practices of their inhabitants. However, transhumant social groups through adaptation and resistance strategies succeeded on maintaining their ancestral mobilities. The aim of this texts it o make a balance of the trajectory of the research about this issue that has been carried out in the central west area of the Chilean Argentine border since 2000. The following questions guide this revision: what have been the epistemological turns that guided our studies about this borderland?; What kind of textual and visual representations had been involved in this research? And, lastly, which perspectives did the case study offer to challenge the border paradigm in which we had formed?. Which new lines of research stem from this perspective?

Keywords: Border, mobilities, cultural relations. 
Cuando comenzamos a analizar la frontera entre Argentina y Chile, advertimos que la teoría del conflicto había calado tan hondo durante las décadas de los setenta y los ochenta, que los investigadores continuaban interpretando desde la misma perspectiva ámbitos geográficos limítrofes como la Patagonia, a la vez que describían y analizaban este espacio hasta el límite internacional desde una postura nacionalista y estado-céntrica. Tratando de ir más allá de este enfoque, en el contexto de fines de los noventa, nuestra tesis buscó sumar la mirada del otro lado de la frontera tanto desde el punto de vista académico como vivencial. Así, en primera instancia advertimos que, durante la constitución de los estados nacionales a partir de 1850, en ambos países se dieron procesos similares en la construcción de la frontera como confín del estado. En segunda instancia, las instituciones escolares, en tanto configuradoras de la nación, cumplieron un papel ideológico en la definición del "otro" trasandino como también los mapas, las imágenes y los museo (Anderson, 1991).

En resumen, lo visualmente institucionalizado contribuyó y acentuó las diferencias nacionales e identitarias en los contextos citados.

Desde los 2000, proponemos que las fronteras son lugares (Agnew, 1987) -adyacentes a los límites internacionales- en las que se producen encuentros y desencuentros (De Souza Martins, 1996: 1) de diferentes actores, a distinta escala. Son lugares no constituidos únicamente por "la línea" limítrofe, pero influidos por ella. Se trata de lugares móviles porque en ellos se producen territorializaciones y reterritorializaciones ${ }^{4}$ (Haesbaert da Costa, 2004: 312) que al mismo tiempo que mantienen dinámicas históricas son afectados por procesos actuales, es decir, se perciben simultáneamente temporalidades y espacialidades de prácticas culturales tradicionales y del mundo global. A la vez, como todo proceso de construcción social, refleja constantes transformaciones por parte de quienes los habitan, circulan y organizan política, económica y culturalmente.

Buscamos explicar en este texto cómo llegamos a estas conclusiones; cómo fuimos desnaturalizando nuestro concepto de frontera; cómo advertimos las múltiples presencias de actores desdibujados en la construcción histórica de la espacialidad estatal; cómo estos pastores transitan y negocian con otros y cómo las representaciones del lugar de la frontera -pasadas y presentes- se resignifican constantemente. En síntesis procuramos comprender cómo el concepto de frontera en el que nos habíamos formado se fue reformulando y, a la vez, sigue en movimiento en la medida que continuamos reflexionando sobre sus resignificaciones en cambiantes contextos.

Nuestro estudio de caso, la frontera argentino chilena que corresponde actualmente a la provincia de San Juan (Argentina) y las Regiones de Coquimbo y Valparaíso (Chile), nos permitió proponer tres variables epistemológicas desde donde se construye el lugar de las fronteras: la multiescalaridad, los dos lados de la frontera y la multiplicidad de sentidos del lugar.

\section{Múltiples escalas: muchas miradas}

La multiescalaridad nos proporcionó diferentes perspectivas desde donde se establecen los lugares de frontera, por ejemplo; las globales, la de los estados nación, las de las regiones y también las dinámicas locales y cotidianas.

Entendemos por "desterritorialización y reterritorialización" al proceso por el cual el capital en su reestructuración barre con las territorialidades existentes para instalar nuevas formas de organización política y cultura (Harvey, 1992) 
Fueron las fuentes tanto tradicionales (archivos, mapas, entrevistas) y actuales (medios de comunicación, señalética vial, devociones religiosas) las que nos permitieron comprender estas múltiples perspectivas escalares.

Las diferentes fuentes contribuyeron a identificar las miradas sobre las fronteras configuradas desde diversas escalas, pues ellas nos aproximaron a las interpretaciones de individuos e instituciones situados en contextos espaciales y temporales heterogéneos, ampliando el foco con el que analizamos las fronteras. Por ejemplo, las fuentes de las redes globales nos permitieron entender la centralidad de la frontera andina ante los intereses de la minería trasnacional y el turismo. Al indagar sobre las políticas de los gobiernos regionales -fuentes municipales y periodísticas por ejemplo- advertimos discursos de aislamiento y periferia de dicho ámbito. El estudio de las entrevistas nos posibilitó ahondar en el conocimiento de las dinámicas de vida de los pastores trashumantes en los altos valles andinos. La continuidad temporal de la trashumancia nos descubrió la movilidad de y en la frontera en la escala cotidiana de los pastores. Entonces en base a la propuesta de Urry (2007) advertimos que, los pastores se mueven en la frontera y la frontera se mueve con ellos y, en consecuencia, viajan los lugares y con ellos viajan las culturas.

Así, entendimos que estas formas culturales de habitar y construir el espacio continúan existiendo en el viaje, en el tránsito, en la circularidad de los itinerarios que son condición y posibilidad de su permanencia. Sin embargo, en la medida que acciones a escala estatal o global han intentado controlar o dirigir los trayectos de los pastores, intervenir y/o reconvertir sus prácticas, se ha sugerido -y aún se propone- la supuesta "desaparición" de la forma de vida de los "cabreros" chilenos en los altos valles sanjuaninos.

\section{Los dos lados de la frontera}

Nuestros textos buscaron incorporar ambos lados de la frontera como forma de superar la visión unilateral y de carácter nacional, que históricamente encerró el análisis a un territorio de un único estado -hasta el límite internacional-. Así se dejaba de lado las tensiones, vínculos y articulaciones que intervenían en el proceso de constitución de la frontera. Para ello trabajamos abordando la frontera desde los dos lados en base a las producciones bibliográficas académicas e institucionales (Aranda, 1971; Gambier, 1986; Escolar, 1996/1997; Castillo, 2003; Cialdella y Dubroeucq, 2003; Bendini y Nogués, 2005; Medinaceli, 2005; González Coll, 2008; Bendini y Steimbreger, 2010; Silla, 2010; Studermann, 2010; Tomasi, 2013), la información de documentos oficiales, archivos periodísticos y entrevistas producidas y/o realizadas tanto en Argentina como en Chile.

Cuando abordamos las formas de representar la frontera observamos que históricamente y en el presente en los mapas, planos catastrales e infografías que parten de las instituciones oficiales y de investigación, mantienen la imagen del territorio hasta el límite internacional, acentuando así el contorno delimitador, que contribuyó a la construcción del espacio estatal nacional en ambos países ${ }^{5}$.

Los límites pocas veces fueron una línea recta contigua como muestra el imaginario cartográfico sino que fue un ámbito más bien permeable y poroso (ver Zusman y Hevilla, 2014). 
En un comienzo, en nuestros trabajos, intentamos representar lo que ocurría en la frontera argentino-chilena solapando imágenes territoriales de las propiedades limítrofes -producidas por el catastro sanjuanino- y los itinerarios de los pastores andinos -localizados cartográficamente por el profesor Mariano Gambier (1986:20)- en el periodo comprendido de 1850 a 1990. Este solapamiento de prácticas sobre un mismo espacio cuestionó las argumentaciones tradicionales respecto a las causas del pastoreo de crianceros chilenos en los altos valles sanjuaninos. Desde nuestro punto de vista estas dinámicas explican dicha trashumancia basadas en relaciones familiares y de nacionalidad entre los dueños de la tierra y los que se movilizan para pastorear en estos valles. En efecto, en el periodo analizado las entrevistas y los archivos nos mostraron que los propietarios eran chilenos y los pastores también; los contratos de arrendamiento y del cuidado del ganado se efectuaban entre habitantes de la IV Región en Chile. En consecuencia, podemos afirmar que son los lazos culturales históricos entre los propietarios y los pastores chilenos los que mantuvieron la continuidad de una práctica que comienza en la costa chilena hasta el territorio argentino al ritmo de las estaciones y las necesidades de los animales (Figuras $N^{\circ} 1$ y $N^{\circ} 2$ ).

Figura $\mathrm{N}^{\circ} 1$

Gráfico catastral de propiedades

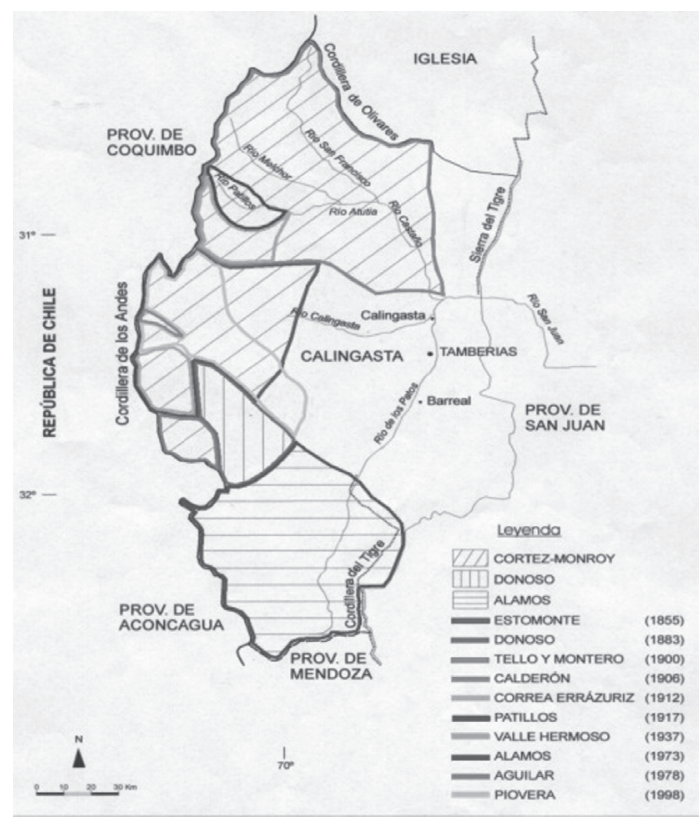

Figura $\mathrm{N}^{\circ} 2$

Zonas de pastoralismo altoandino

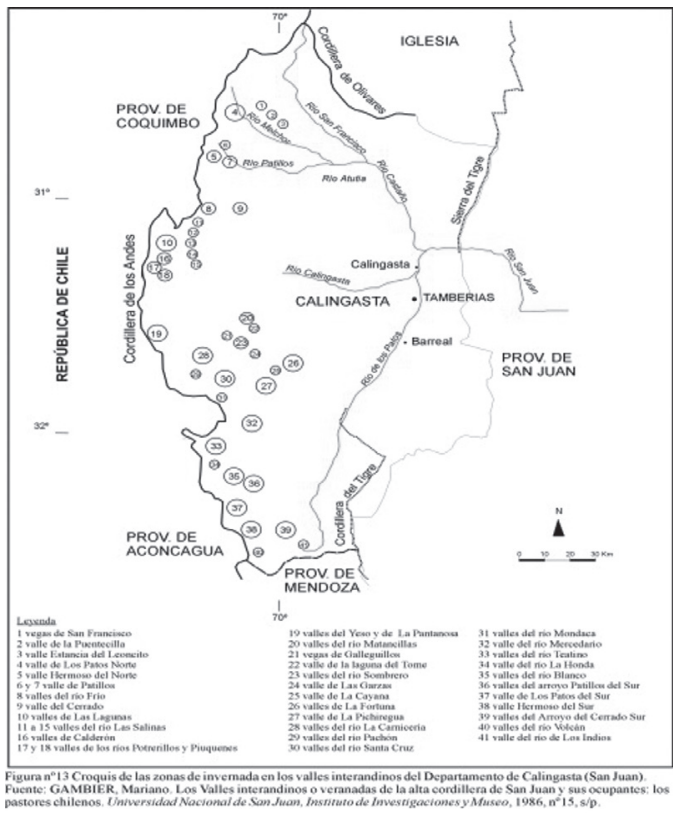

Fuente: Hevilla, 2001.

Cabe destacar que a pesar de nuestro esfuerzo por incluir los dos lados de la frontera, en la producción de imágenes propias no logramos superar las formas tradicionales en la que aprendimos a dibujar y leer los mapas (Lois y Hollman: 2013, Lois: 2014), recurriendo a los convencionalismos de la producción de imágenes cartográficas como mostramos en la figura 1 y 2. También cuando trabajamos sobre las inversiones mineras trasnacionales y el proyecto de camino inter- 
nacional de Agua Negra ${ }^{6}$ en los departamentos de Iglesia y Calingasta en San Juan, los representamos en un mapa que finalizaba en el límite internacional (ver Figura $\mathrm{N}^{\circ} 3$, realizada en 2007).

Figura $\mathrm{N}^{\circ} 3$

Inversiones mineras en la provincia de San Juan (Argentina)

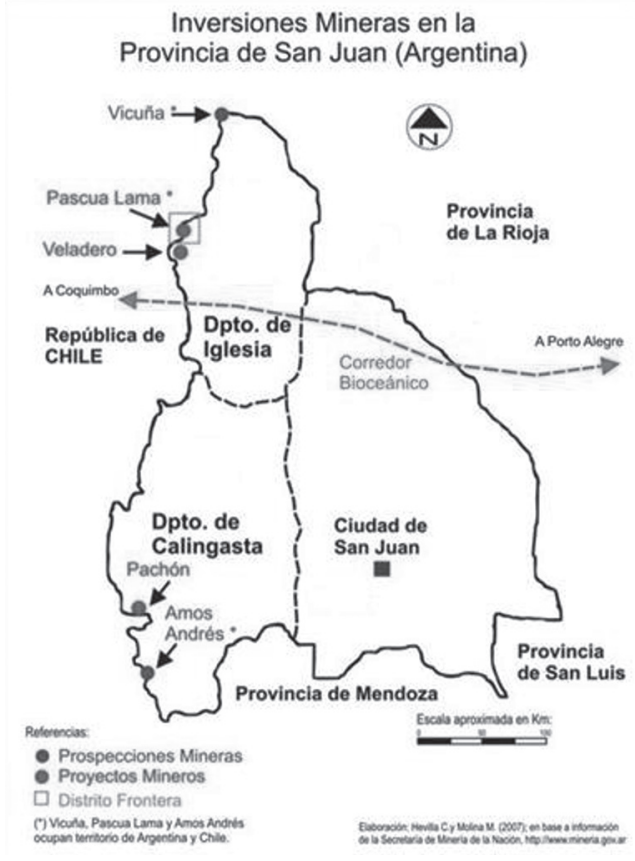

Fuente: Hevilla y Molina (2007: 210).

Sin embargo, en las presentaciones que ilustraban nuestras ponencias lográbamos subvertir las posturas cartográficas tradicionales y señalar a los actores menos tenidos en cuenta en las fronteras, en parte gracias al análisis de las imágenes pictográficas. Estas nos permitieron comprender y comprobar estos lazos culturales pasados y presentes a un lado y otro de la frontera andina. Un ejemplo de ellas es la devoción a ambos lados de la cordillera de la Virgen de AndacoIlo, la peregrinación de los promesantes sanjuaninos hasta el santuario chileno, la participación en sus bailes y la reproducción de la festividad en la provincia de San Juan (Figura $N^{\circ} 4$ ).

Las peregrinaciones religiosas de los sanjuaninos a la festividad de Andacollo en Chile nos señalan que la cordillera de los Andes no fue un obstáculo para que la celebración religiosa trascendiera el límite impuesto por los Estados, ampliando su área simbólica de influencia, traspasando las montañas y dando muestras de la continuidad de los vínculos culturales de una región que estuvo históricamente unida. La recreación de prácticas religiosas de origen chileno en áreas bajo dominio del Estado argentino, por parte de pobladores de ambos países, llevó a que la presencia

El Camino Internacional de Agua Negra denominado corredor bioceánico es un proyecto antiguo en la provincia de San Juan y en la Cuarta región Chilena. Los datos sobre este camino se pueden rastrear en Musri et al., 1998). 
Figura $\mathrm{N}^{\circ} 4$

Fiesta en Honor a la Virgen del Rosario de Andacollo (Chile) 1838

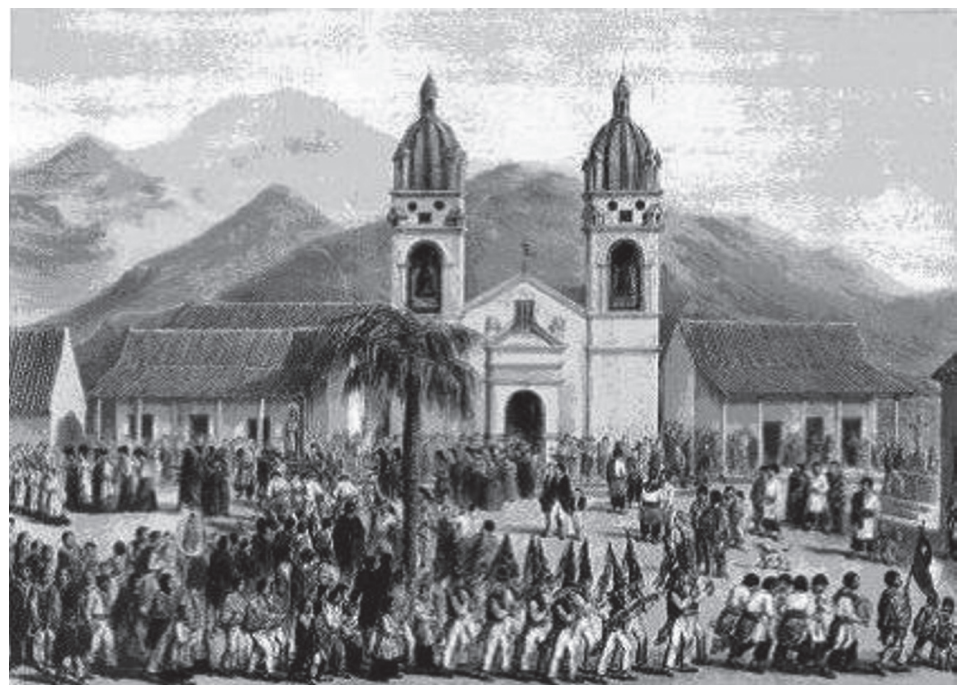

Fuente: Gay, 1938.

de la cultura popular chilena en la zona rural y luego en las ciudades sanjuaninas cobrara mayor visibilidad. De esta manera la frontera cultural del territorio no coincidió con la frontera estatal nacional. En resumen pensamos que la religiosidad popular trasciende y amplía su área simbólica, haciendo caso omiso de las divisiones jurídico-estatales representadas en el límite internacional.

Actualmente, la celebración de la festividad de Andacollo en San Juan, permite confirmar las prácticas de la simultánea integración-diferenciación que se dan en las fronteras (Figura $N^{\circ} 5$ ). Así, a la vez que participan conjuntamente argentinos y chilenos en dicha celebración, la pertenencia nacional diferenciada se refuerza simbólicamente por el uso de las banderas nacionales de los dos países (Hevilla, 2001).

Al trabajar con una diversidad de imágenes -pictografías, caricaturas, fotografías- pudimos plasmar en nuestras representaciones gráficas los trayectos, los itinerarios (materiales y simbólicos) de los habitantes de la frontera. En ellos, si bien el límite internacional ocupó el centro de la zona de estudio, esta línea no tuvo mayor preeminencia que otros tres aspectos: las porosidades que marcan la existencia de pasos cordilleranos (propios de la formación geomorfológica andina y que rompen con el imaginario de la cordillera como muralla); las movilidades temporales de los pastores, y las relaciones de circulación de otros actores articulados en redes locales y/o trasnacionales ${ }^{7}$. (Figuras $\mathrm{N}^{\circ} 6$ ).

Esta forma de representar la frontera ha sido imitada por editores locales en libros funcionales a los gobiernos de ambos países en el contexto de integración de estos últimos años. Estas representaciones buscan por un lado, atenuar los efectos de una década de frontera sanitaria y contribuir a legitimar la necesidad del corredor bioceánico de Agua Negra entre San Juan y La Serena. La deconstrucción de la mirada del "otro invasor" o "expansionista" trasandino ha necesitado de la recuperación de tradiciones históricas en común y, en menor medida, con la proposición de otros mapas no oficiales que las resalten (Muñoz Lorenzo, 2014: 30). 
Figuras $\mathrm{N}^{\circ} 5$

Celebración de los bailes en honor a la Virgen de Andacollo en San Juan
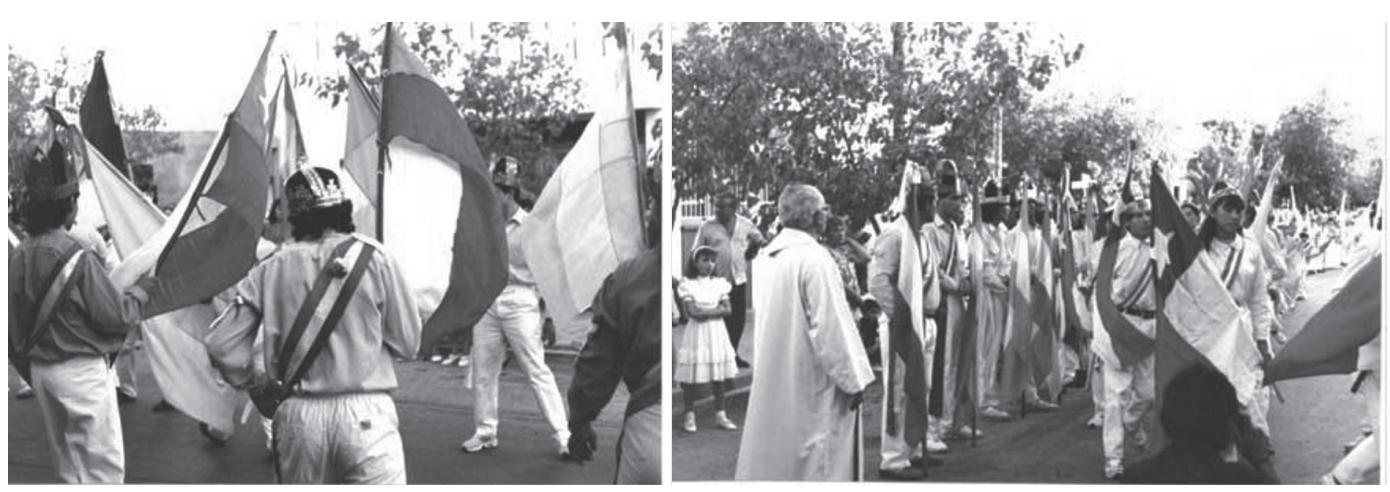

Fuente: Giuliani (1995).

La línea contenedora de los estados nacionales perdió firmeza (fue difuminada) para dejar ver otros itinerarios que la atravesaron y la atraviesan, así como también las variaciones de dichos trayectos.

Figura $\mathrm{N}^{\circ} 6$

Movilidad de los pastores en los Andes
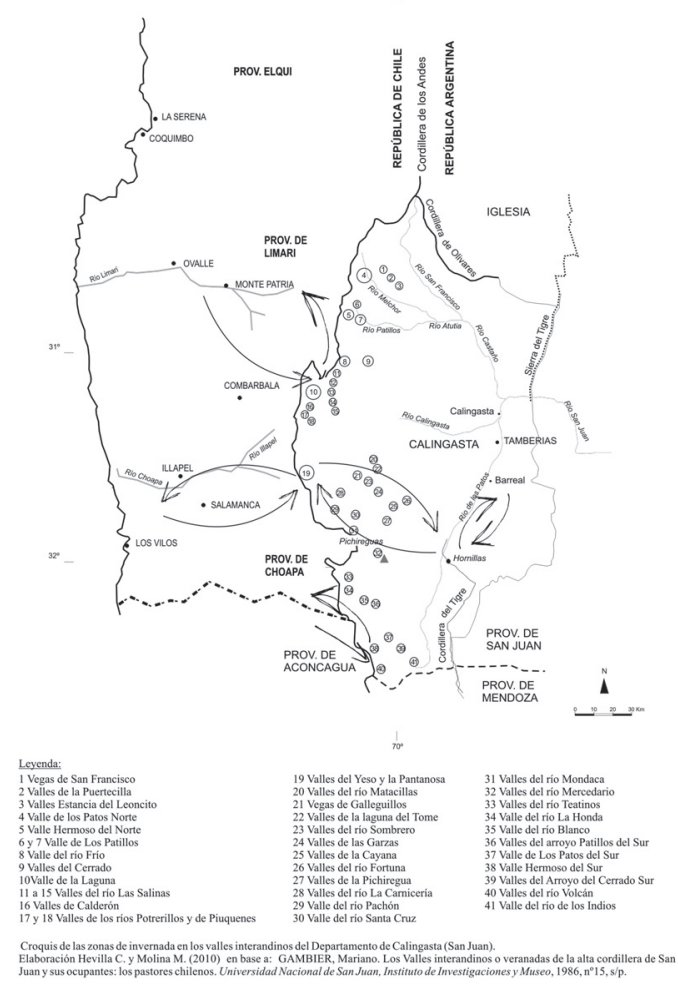

Fuente: Hevilla y Molina (2010). 
De esta forma confeccionamos otros mapas que dieron cuerpo (con los recursos conocidos líneas, colores, símbolos cartográficos, flechas, curvas de itinerarios) a las movilidades de "viejos" y "nuevos" actores y a la convivencia y yuxtaposición entre las mismas. El estado no fue excluido de las imágenes porque su poder se mantiene $y$, a la vez, se va transformando en la interacción con otros actores locales y globales.

En este sentido, la frontera no fue representada hasta el límite de cada país sino que ocupó un lugar central en nuestras imágenes, tal como nos lo revelaban el análisis y las conclusiones del trabajo de campo.

Algunos de los problemas que tuvimos que encarar fueron ¿cómo representar a todos los actores y sus movilidades en las fronteras? y ¿cómo incorporar a los pastores sin recurrir a la simbología tradicional de los mapas? Este es uno de los desafíos a nuestra propia propuesta que pensamos quedó mejor plasmada en 2007, en donde representamos las divisiones internacionales, las jurídico-administrativas de la provincia y las regiones, las empresas trasnacionales mineras, el turismo en ambos lados de cordillera, los animales autóctonos, el camino internacional de Agua Negra, y la zona de pastoreo altoandino en la actualidad (Figura $N^{\circ} 7$ ).

Figura $\mathrm{N}^{\circ} 7$

Las representaciones del lugar en las mediaciones comunicativas

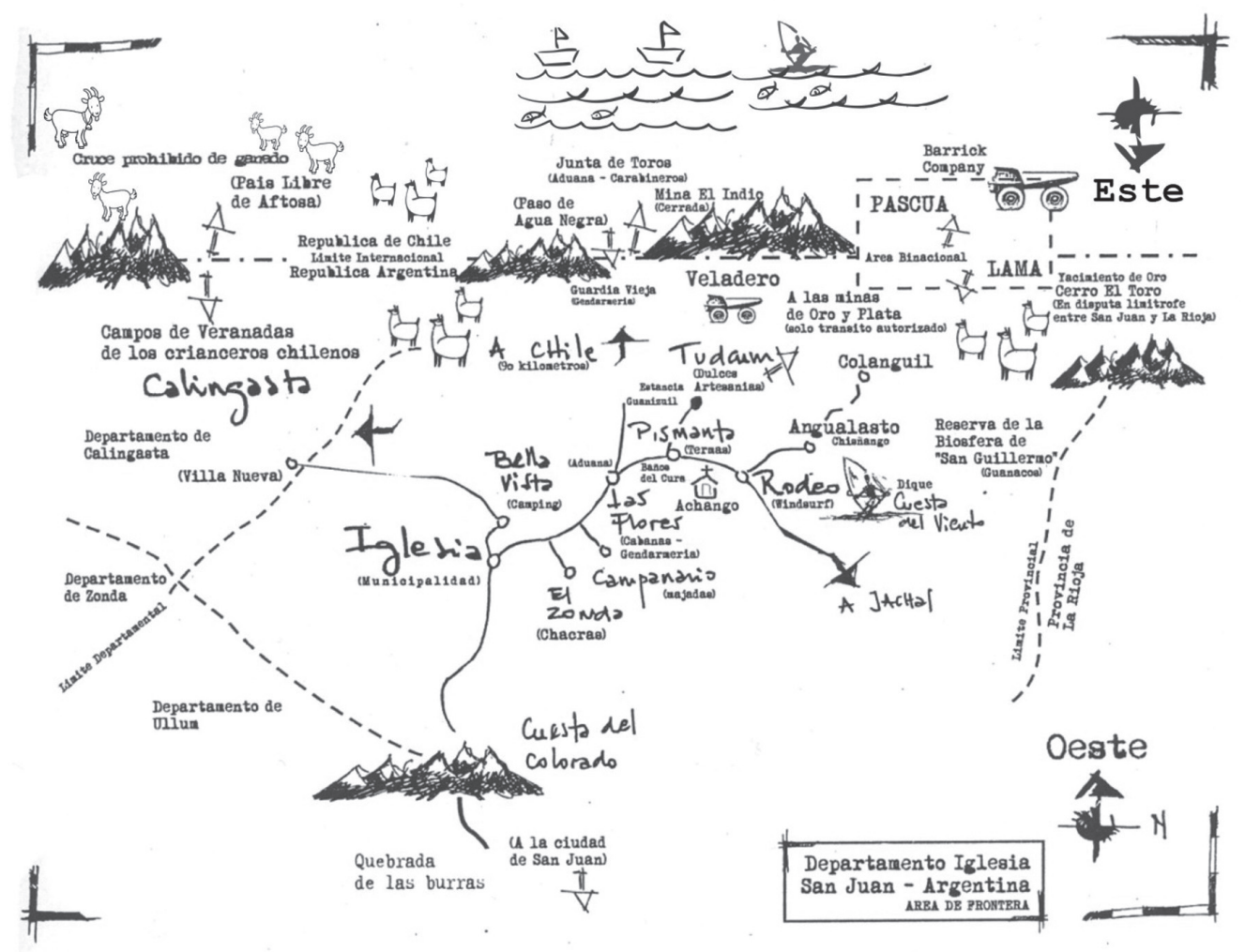

Fuente: Molina (2007). 
En esta figura expresamos la frontera que fluye con trayectos e itinerario de ida y vuelta sobre los límites jurídicos, traspasando montañas que no son murallas, pero que contienen hitos limítrofes. Su orientación hacia el oeste rompe la hegemonía norte -sur; lo que nos llevó también a pensar como desarticular el eje este-oeste, ya que estas convenciones varían desde la posición de los diferentes actores. Así, entendemos que esta representación-que repensamos constantemente- se acerca más a la frontera que estudiamos.

En resumen el estudio de las imágenes presentadas contribuyó a romper con la frontera como lugar de diferenciación y poner en juego al mismo tiempo la idea de encuentro (Jose de Souza Martins: 1996).

\section{Sentidos de lugar en la frontera (Massey, 1993): un lugar, múltiples lugares...}

Durante los noventa en San Juan, en pleno auge de la instalación de empresas trasnacionales mineras en los departamentos de frontera, trabajamos -con el apoyo del proyecto Antorchas-los procesos de desterritorialización y reterritorialización en el departamento de Iglesia (San Juan) y la construcción de nuevos sentidos de lugar en el libro: Viajes y Geografías. En él advertimos tres sentidos del lugar: Iglesia era a la vez, "un lugar central" para la minería trasnacional articulado en las redes globales de las compañías mineras, "un lugar de frontera" para la tradición de pastoreo que se acomodaba a los cambios negociando con los gobiernos y con las empresas trasnacionales, y, finalmente, un "lugar único y vacío" para los emprendimientos turísticos nuevos que centraron su actividad en los deportes náuticos en el dique de Cuesta del Viento.

Estos sentidos de lugar del departamento fronterizo de Iglesia nos permitieron reafirmar la fluidez de la frontera. Así propusimos que este ámbito puede ser, al mismo tiempo, un territorio central y periférico que se mueve al compás de las territorializaciones y reterritorializaciones de los actores locales y globales que actúan a diferente escala (Haesbaert Da Costa, 2004; Zusman et al., 2007).

\section{A modo de conclusión: nuevos enfoques sobre fronteras cambiantes}

Los cuestionamientos a los conceptos tradicionales de frontera que logramos con nuestro estudio de caso nos han permitido trabajar, en estos 15 años, nuevas líneas de investigación. De ser la frontera una zona considerada por los estados nación y por los gobiernos regionales como un ámbito a conquistar, despoblado, periférico; pasó a adquirir una centralidad económica articulada con redes globales.

Los giros epistemológicos de nuestros estudios buscaron comprender la frontera argentino-chilena como un ámbito multiescalar, un área afectada por los procesos globales en el que también persisten prácticas culturales históricas tradicionales y específicas.

La relación entre las prácticas globales, estatales y locales sobre este ámbito generó otros trabajos que contemplaron el discurso de la apertura de fronteras de la época de integración 
(décadas de 1990 y 2000), contrapuestos con acciones estatales de control. Es decir, mientras el capital trasnacional amplió su posibilidad de movimiento en la frontera, los pastores trashumantes se encontraron con restricciones oficiales a sus desplazamientos tradicionales, debido a los controles fitosanitarios que se extendieron por más de una década (2001-2013). En esta línea profundizamos tanto en el mundo de los pastores -con sus estrategias de adaptación y resistencia- (Hevilla et al., 2006) como en las prácticas de los organismos oficiales de control que mantuvieron la presencia y el dominio de los estados nación -gendarmería, aduana, control fitosanitario- (Hevilla y Zusman, 2007; Hevilla, 2014). También nos adentramos en el análisis de las empresas mineras y sus vínculos globales. Con esto queremos decir que en algunas coyunturas estos valles fronterizos cedieron a la centralidad de las políticas de sus países, es decir, vivieron de espalda al límite internacional, en otros momentos mantuvieron sus prácticas espaciales sin importar el límite y/o se adaptaron a las necesidades del comercio nacional e internacional incorporándose al engranaje de las redes globales.

Revisando las formas de representar esta frontera hemos intentado desestructurar nuestro aprendizaje visual, proponiendo otra alternativa también cargada de sentido que se acerca más a los resultados de nuestras investigaciones. Así nos alejamos de los mapas aprendidos que suponen una identificación de la representación oficial y estática como reflejo de la realidad. Por ejemplo las devociones a la Virgen de Andacollo, los parentescos generados antiguamente en ambas bandas de la Cordillera, el pastoralismo, dejaron al descubierto la continuidad de lazos familiares culturales y de nacionalidad más allá de las fronteras de los Estados.

Actualmente mientras los estados nacionales cordilleranos se movilizan para adecuar los territorios nacionales o provinciales a las exigencias de los mercados globales (mineros y turísticos); sus autoridades buscan estrategias materiales y simbólicas destinadas a otorgar continuidad y legitimar sus formas de construcción de poder. A tal fin se buscan nuevas prácticas para recrear los valores nacionales. Esta fue otra de las líneas de trabajo, analizar la reproducción turística del cruce sanmartiniano durante las campañas independentistas, que realiza el gobierno de San Juan (Hevilla, 2016). Esta ruta histórica resignifica los contenidos del siglo XIX, buscando legitimar las actuaciones presentes del gobierno provincial -las autoridades e invitados son presentados como continuadores de la gesta sanmartiniana- tanto en relación a la política regional (competir turísticamente con Mendoza) como en relación a las políticas de integración con Chile. A su vez, dicha reproducción mercantiliza la historia, el paisaje y el itinerario, al buscar sumarlos a la práctica turística. La revalorización patrimonial de las rutas independentistas también puede asumirse como la presencia estatal provincial que -con otra cara-reterritorializa el espacio y lo ocupa en esta recreación histórica volviendo a conquistar el territorio.

Hemos tratado de describir los procesos actuales que se dan en los valles interandinos de la frontera sanjuanino-chilena advirtiendo que el control ha cambiado de máscara pero continua existiendo en las fronteras. Desde fronteras sanitarias que no terminaron con la tradición de la trashumancia de pastores andinos hasta la patrimonialización de rutas históricas que visibilizan a estos habitantes como parte del paisaje a descubrir.

Así, hoy las dinámicas espaciales, temporales y culturales son puestas en la escena mediática (artículos periodísticos, documentales, películas, fotografías, propagandas oficiales) a través de una nueva política de representación. Sin embargo, para los habitantes de la frontera, especialmente para los pastores andinos; la misma no es un proceso desconocido en sus vidas y mucho 
menos un espectáculo; es el lugar donde transcurren sus recorridos vitales, en el que acaecieron el de sus abuelos y, probablemente continúen el de sus hijos.

Como propone Hasbaert (2011:51) estas identidades no se están diluyendo en la globalización, pueden estar fortaleciéndose en la propia movilidad en formas más hibridas, resaltando su carácter múltiple, liminar y transfronterizo.

\section{Referencias bibliográficas}

AGNEW, J. Place and Politics: The Geographical mediation of state and society. Winchester: Allen \&Unwin, 1987.

ANDERSON, B. Comunidades imaginadas. Reflexiones sobre el origen y difusión del nacionalismo. México: FCE, 1991.

ARANDA, X. Algunas consideraciones sobre la trashumancia en el Norte Chico. Informaciones Geográficas, 1971, Vol. 20, p. 141-169.

BENDINI M.I., TSAKOUMAGKOS, P. y NOGUÉS, C. Los crianceros trashumantes en Neuquén. En: BENDINI, M y NOGUÉS, C. (editores). Crianceros y chacareros en la Patagonia Austral. Buenos Aires: Editorial La Colmena, 2005, p.23-40.

BENDINI, M.I. y STEIMBREGER, N.G. Dinámicas territoriales y persistencia campesina: redefinición de unidades y espacios de trabajo de los crianceros en el norte de la Patagonia. Revista Transporte y Territorio, 2010, Nº 3 , p. 59-76.

CASTILLO, G. La vuelta de los años: reseñas y perspectivas sobre las comunidades, el pastoreo y la trashumancia en la región semiárida de Chile. En: LIVENAIS, P. y ARANDA, X. (editores). Dinámica de los sistemas agrarios en Chile árido: la región de Coquimbo. Santiago de Chile: LOM ediciones, 2003, p. 33-65.

CIALDELLA, N. y DUBROEUCQ, D. La Trashumancia de cabras en Chile: un modo de gestión adaptado a las zonas áridas En: LIVENAIS, P. y ARANDA, X. (editores). Dinámica de los sistemas agrarios en Chile árido: la región de Coquimbo. Santiago de Chile: LOM ediciones, 2003, p. 327-340.

ESCOLAR, D. Prácticas espacio temporales, poder e identidad entre los baqueanos de los Andes sanjuaninos. Cuadernos del Instituto Nacional de Antropología y pensamiento latinoamericano, 1996/1997, No 17, p. 17-37.

GAMBIER, M. Los valles interandinos o veranadas de la alta cordillera de San Juan y sus ocupantes los pastores chilenos. Universidad Nacional de San Juan, Instituto de Investigaciones y Museo, 1986.

GONZALEZ COLL, M. Crianceros trashumantes patagónicos. Revista TEFROS, Vol. 6, № 1, 2008. Disponible en Internet:

file:///C:/Users/Usuario/Downloads/Dialnet-CriancerosTranshumantes-5008084\%20(1).pdf 
HAESBAERT DA COSTA, R. O Mito da desterritorialização: do "fim dos territórios" à multirretirritorialidade. Río de Janeiro: Bertrand, 2004.

HAESBAERT DA COSTA, R. Viviendo en el límite: los dilemas del hibridismo y de la multi/trasnterritorialidad. En: ZUSMAN, P.; HAESBAERT, R.; CASTRO, H. y ADAMO, S. (editores). Geografías Culturales. Aproximaciones, intersecciones y desafíos. Buenos Aires: Editorial de la Facultad de Filosofía y Letras, 2011, p.49-76.

HARVEY, D.A Condição Pós-Moderna. São Paulo: Edições Loyola, 1992.

HEVILLA, C. El estudio de la frontera en América. Una aproximación bibliográfica. Biblio 3W. Revista Bibliográfica de Geografía y Ciencias Sociales, 1998. Disponible en Internet: http://www.ub/ geocrit/B3w-125.htm

HEVILLA, C. El Estado innovador: estrategias de control y contacto en la frontera. Scripta Nova, Scripta Nova. Revista Electrónica de Geografía y Ciencias Sociales, 2000, Vol. 51, № 69 (51). Disponible en Internet: http://www.ub.es/geocrit/sn-69-51.htm

HEVILLA, C. La configuración de la frontera centro-oeste en el en el proceso de constitución del Estado argentino (1850-1902). Barcelona: Tesis doctoral, Universidad de Barcelona, 2001.

HEVILLA, C. Fiesta Migración y Frontera. Scripta Nova. Revista Electrónica de Geografía y Ciencias Sociales, 2001, Vol. 106, № 94 (106). Disponible en Internet: http://revistes.ub.edu/index.php/ ScriptaNova/article/view/431

HEVILLA, C. Los estudios de frontera: "con o sin indios". Conceptos para la interpretación de los procesos de configuración de frontera en San Juan en la época tardía colonial y estatal nacional. Instituto de Investigaciones Arqueológicas y Museo-FFHA-UNSJ, 2004, № 25.

HEVILLA, C. Los Viajeros de las alturas: Narrativas de viajeros y científicos sobre los Andes Argentino-Chilenos en el siglo XIX. En: ZUSMAN, P.; LOIS, C. y CASTRO, H. (editores). Viajes y geografías. Exploraciones, turismo y migraciones en la construcción de lugares. Prometeo: Buenos Aires, 2007, p. 67-92.

HEVILLA, C. Instituciones de control, familias y trashumancia en las fronteras andinas argentino-chilenas (1996-2013). En: BONASTRA, Q.; VASCONCELOS P. JUNIOR, M.; TAPIA, M. (editores). Actas del XIII Coloquio Internacional de Geocrítica: El control del espacio y los espacios de control. Barcelona: Universidad de Barcelona, 2014a.

HEVILLA, C. Mundos cordilleranos: familias, poderes y trashumancia. En: BORSDORF, A.; SÁNCHEZ, R.; HIDALGO, R.; ZUNINO, H.M. (editores). Los riesgos traen oportunidades. Transformaciones globales en Los Andes sudamericanos. Santiago de Chile: Instituto de Geografía, Pontificia Universidad Católica de Chile/Academia de Ciencias Austriaca/Universidad de Innsbruck, 2014b, p. 141-150.

HEVILLA, C. Utopías en las fronteras andinas. En: BENACH, N.; ZAAR, M.; VASCONCELOS, P. y JUNIOR, M. (editores). Actas del XIV Coloquio Internacional de Geocrítica: Las utopías y la construcción de la sociedad del futuro. Barcelona: Universidad de Barcelona, 2016. 
HEVILLA, C. y ZUSMAN, P. Las caricaturas periodísticas de finales de siglo XIX en la constitución de las fronteras del Estado Nación argentino. Revista Litorales, Año 4, N 5, 2005, p. 1-21.

HEVILLA, C.; ZUSMAN, P. y MOLINA, M. Geografías de los tiempos lentos. En: NOGUÉ, J. y ROMERO, J. (editores). Otras Geografías. Valencia: Tiran Lo Blanch, 2006, p. 10-19.

HEVILLA, C. y MOLINA M. Territorialidades en movimiento: desplazamientos y reconfiguraciones territoriales ante las inversiones extranjeras en ámbitos de fronteras. En: ZUSMAN, P.; LOIS, C. y CASTRO, H. (editores). Viajes y geografías. Exploraciones, turismo y migraciones en la construcción de lugares. Prometeo: Buenos Aires, 2007, p. 203-224.

HEVILLA, C. y ZUSMAN, P. Movilidades y construcción de nuevas territorialidades en la frontera Argentino-Chilena. Scripta Nova. Revista Electrónica de Geografía y Ciencias Sociales, 2007, Vol. $\mathrm{XI}, \mathrm{N}^{\circ} 245$ (22). Disponible en Internet: http://www.ub.es/geocrit/sn/sn-24522.htm

HEVILLA, C. y ZUSMAN, P. Diez años de estudios de fronteras en los coloquios internacionales de Geocrítica. Diez años de cambios en el mundo, en la Geografía y en las Ciencias Sociales, 1999-2008. En: X Coloquio Internacional de Geocrítica, Diez años de cambios en el mundo, en la Geografía y en las Ciencias Sociales, 1999-2008. 2008. Disponible en Internet: http://www.ub.es/ geocrit/-xcol/108.htm

HEVILLA, C. y ZUSMAN, P. Borders which unite and disunite: Mobilities and development of new territorialities on the Chile - Argentina frontier. Journal of Borderland Studies, dossier Mercosur, 2009, Vol. 24, №3. Disponible en Internet: https://journals.uvic.ca/index.php/borderlands/article/ view/538

HEVILLA, C. y MOLINA, M. Trashumancia y nuevas movilidades en la frontera argentino-chilena de los andes centrales. Revista Transporte y Territorio, 2010, № 3, p. 40-58.

HEVILLA, C. y ZUSMAN, P. Panamericanismo y arbitraje en conflictos de límites: la participación de Estados Unidos en la definición de la frontera argentino-chilena en la Puna de Atacama (1899). Cuadernos de Geografía: Revista Colombiana de Geografía, 2014, Vol. 23, N² 2, p. 95-106.

LOIS, C. Imagen cartográfica e imaginarios geográficos. Los lugares y las formas de los mapas en nuestra cultura visual. Scripta Nova. Revista Electrónica de Geografía y Ciencias Sociales, 2009, Vol. XIII, N² 298. Disponible en Internet:

http://www.ub.es/geocrit/sn/sn-298.htm).

LOIS, C. y HOLLMAN, V. (coordinadores). Geografía y cultura visual. Los usos de las imágenes en las reflexiones sobre el espacio. Rosario: Prohistoria Ediciones UNR, 2013.

MARTINS DE SOUZA, J. O tempo da fronteira. Retorno à controvérsia sobre o tempo histórico da frente de expansão e da frente pioneira. Tempo Social, 1996, Vol. 8, No 1. Disponible en Internet: http://www.revistas.usp.br/ts/article/view/86141

MASSEY, D. Questions of Locality. Geography, 1993, p. 142-149. 
MEDINACELI, X. Los pastores andinos: una propuesta de lectura de su historia. Ensayo bibliográfico de etnografía e historia. Boletín del Instituto Francés de Estudios Andinos, 2005, Vol. 34, № 3, p. 463-474.

MUÑOZ LORENZO, G. Los trashumantes de la Cordillera de los Andes. Los últimos pastores del hemisferio Sur. San Juan: GHM, 2014.

MUSRI, D.; MALBERTI, S. y HEVILLA, C. La frontera argentino-chilena en San Juan como zona de Integración y Desarrollo (1946-1955). San Juan: Servicio de Publicaciones FFHA, 1998.

SILLA, R. Variaciones temporales, espaciales y estacionales de los crianceros del norte neuquino. Revista Transporte y Territorio, 2010, N 3, p. 5-22.

STUDERMANN HENRÍQUEZ, N. Producción caprina tradicional. Perspectivas desde la Antropología. En: HERNÁNDEZ ARACENA, R. y PEZO ORELLANA, L. (editores). La ruralidad Chilena actual: Aproximaciones desde la antropología. Santiago de Chile: CoLibris, 2010, p.325-366.

TOMASI, J. Espacialidades pastoriles en las tierras altoandinas. Asentamientos y movilidades en Susques, puna de Atacama (Jujuy, Argentina). Revista de Geografía Norte Grande, 2013, № 55, p. 67-87.

URRY, J. Culturas Móviles (Introducción). En: ZUSMAN, P.; LOIS, C. y CASTRO, H. (coordinadores). Viajes y geografías. Exploraciones, turismo y migraciones en la construcción de lugares. Buenos Aires: Prometeo, 2007, p.17 a 29.

ZUSMAN, P. Entre el lugar y la línea: la constitución de las fronteras coloniales patagónicas (17801792). Fronteras de la Historia, 2001, Vol. 6, p. 37-60.

ZUSMAN, P.; LOIS, C. y CASTRO, H. (coordinadores). Viajes y geografías. Exploraciones, turismo y migraciones en la construcción de lugares. Buenos Aires: Prometeo, 2007.

ZUSMAN, P.; HAESBAERT, R.; CASTRO, H. y ADAMO, S. Geografías Culturales. Aproximaciones, intersecciones y desafíos. Buenos Aires: Editorial de la Facultad de Filosofía y Letras, 2011.

ZUSMAN, P. y HEVILLA, C. El arbitraje de Estados Unidos y la línea recta en los conflictos de límites latinoamericanos. Geocritiq, Plataforma Digital Iberoamericana para la difusión del trabajo científico, 2014. Disponible en Internet: http://www.geocritiq.com/ 